\title{
Testimonios orales y arte sonoro como estrategias de representación
}

\section{en el antropoceno}

vol 20 / Jun.2019 115-130 pp Recibido: 22-02-2019 - revisado 27-05-2019 - aceptado: 20-06-2019 


\section{ORAL TESTIMONIES AND SOUND ART AS STRATEGIES OF REPRESENTATION IN THE ANTHROPOCENE}

\section{ABSTRACT}

This article is a review of an exhibition project in which artists, social scientists and citizens have collaborated with the aim of opening possibilities, imagining and extending thought towards large-scale environmental processes. Starting from a local context of declining heavy industry, transition towards a computerized society, and an energetic and climatic conflict ravaging Europe. Through the use of oral testimonies and their sound dimension it was possible to create an artistic representation of collective labour identities, amplify those discordant voices and create a new narrative of the steel industry. This interdisciplinary experience was able to look as themes such as the politics of work, those of material objects and the contribution of artistic practices to the Anthropocene debate.

\section{Keywords}

Anthropocene, Sound Art, Carbon, Climate Change, Labour Identity, Steel Industry

\section{RESUMEN}

Este artículo es una recensión de un proyecto expositivo en el que han colaborado artistas, científicos sociales y ciudadanos con el objetivo de abrir posibilidades, imaginar y extender el pensamiento hacia los procesos ambientales a gran escala. Partimos de un contexto local de declive de la industria del acero, de transición hacia una sociedad informatizada y de una Europa sumida en un conflicto energético y climático. Mediante el uso de testimonios orales y su dimensión sonora fue posible crear una representación artística de las identidades colectivas laborales, amplificar esas voces discordantes y crear una nueva narrativa del sector de la siderurgia. Esta experiencia interdisciplinar dio lugar a una reflexión en torno a las políticas del trabajo, las de los objetos materiales y la aportación de las prácticas artísticas al debate del Antropoceno.

\section{Palabras Clave}

Antropoceno, arte sonoro, cambio climático, carbón, identidad laboral, siderurgia 


\section{LOS TIEMPOS DEL CARBÓN}

La construcción de maquinaria y herramientas para edificios y obras públicas son algunas de las más importantes manifestaciones del desarrollo tecnológico de las sociedades industrializadas. Los componentes de coches, trenes, edificios, barcos, puentes, neveras, equipos médicos y las máquinas que los fabrican están hechos en acero. Este material se obtiene añadiendo al hierro cantidades variables de carbono en altos hornos de carbón, se trata de un proceso de "carburización» que supone la base de la industria siderúrgica. Tanto el hierro como el carbono son componentes que se encuentran en abundancia en la Tierra y, dada su variedad y disponibilidad, su producción se desarrolla a gran escala. La extracción de mineral de hierro y la de carbón se lleva realizando desde la prehistoria mediante cada vez más complejas tecnologías que explotan minas subterráneas o a cielo abierto de gran impacto sobre la corteza terrestre. Desde la invención de la máquina de vapor, en el siglo XVIII, esta producción requiere un alto coste de capital humano que ha provocado las luchas obreras y sindicales históricas de la Europa industrial. El carbón es también un combustible necesario en otros múltiples procesos industriales como la generación de electricidad en centrales termoeléctricas o el uso doméstico en calefacción y cocción. La quema de combustibles fósiles produce dióxido de carbono, lo que contribuye al efecto invernadero y por tanto al calentamiento global, a la formación de lluvia ácida y, con todo ello, a la pérdida de biodiversidad. Estas circunstancias hacen que la siderurgia no goce de simpatía entre algunos sectores sociales y que el carbón y el acero susciten una ambivalente idea de rechazo y felicidad. Por un lado, colman nuestros deseos y necesidades, por el otro, son temas de gran significancia debido a su toxicidad y la fragilidad de la estructura económica que los sustenta.

El carbono es el elemento que conforma la base del carbón y otros combustibles fósiles como el petróleo. Además, constituye la base de todos los procesos vitales, se encuentra en una variedad casi infinita de combinaciones y es un componente importante de la atmósfera. La biosfera y la geosfera intercambian carbono con la atmósfera en un lento proceso denominado ciclo del carbono, que junto con el ciclo del nitrógeno y el del agua son claves para hacer a la Tierra capaz de sostener vida. El carbón es un recurso no renovable que requiere de tiempos muy largos para su formación. La acumulación de vegetales muertos hace unos 300 millones de años ha necesitado los 50 millones de años del Carbonífero para convertirse en material fósil. Durante ese tiempo el paisaje planetario dibujado por paleobotánicos, paleontólogos y arqueólogos está cubierto de extensas zonas boscosas que, al producirse un cambio climático, quedaron sepultadas bajo sedimentos terrestres o pantanos, un paisaje de tierras emergidas en un ambiente cuasi tropical. El deterioro vegetal y la descomposición bacteriana facilitaron el proceso de carbonización o acumulación de carbono y los restos quedaron atrapados entre estratos de otras rocas que ahora encontramos a cientos de metros de profundidad.

Este tipo de procesos de depósito de sedimentos y estratificación se repiten en la historia geológica de la Tierra. Cada periodo en el que domina una determinada forma de vida o fuerza climática deja una huella en las capas de la corteza del planeta, incluida la actividad humana. De hecho, durante el 35으 Congreso Internacional de Geología, en 2016 en Cape Town (Sudáfrica), se anunció la emergencia en los registros geológicos de un nuevo estrato que comenzó a depositarse hace unos 10.000 años (Zalasiewicz et al., 2016), lo que llevó a los geólogos a poner punto y final al Holoceno, el período interglacial que ha permitido el desarrollo de la especie humana entre la amplia biodiversidad que conocemos. Esta declaración abrió paso a una nueva era geológica, el Antropoceno, cuyas trazas sobre el planeta son el resultado de las sociedades 
industriales. Este concepto, ya planteado por Crutzen y Stoermer (2000), explica que, con los primeros depósitos de "gases de efecto invernadero" en el hielo glacial y los grandes cambios en los conjuntos bióticos de los lagos, vivimos en una era de transformación irreversible del planeta que se traduce en el cambio climático y la extinción masiva de especies. Los 10.000 años de presencia humana en el planeta de Zalasiewicz, o los 300 años desde la invención de la máquina de vapor de Crutzen y Stoermer son lapsos de tiempo larguísimos a escala humana, pero cortísimos a escala geológica.

Estas declaraciones científicas han dado como resultado que el concepto de Antropoceno haya invadido todos los terrenos de debate y haya provocado una reacción de alarma que proyecta imágenes de un futuro distópico. De repente, la humanidad se ha convertido en una fuerza telúrica, un agente determinante en la evolución geológica de la tierra cuyo impacto altera el planeta de una manera no contada pero definitiva. Las respuestas desde los ámbitos sociales, intelectuales o gubernamentales han sido llamadas a la responsabilidad y manifestaciones de culpa, nostalgia o negación ante un nuevo concepto para un viejo problema. Incluso parece, que, como Desoto (2016) sugiere, ese concepto ha llegado a ser una narrativa recurrente y fácil que oculta responsabilidades. Quizás el Antropoceno sea una especie de continua declaración de crisis o la crónica de una muerte anunciada en las décadas de 1960 y 1970 con el cenit del petróleo y la publicación de diferentes textos científicos que alertaron sobre el futuro del planeta (Carson 1962, Wilson y Matthews 1971, Meadows 1972). Además, a pesar de la organización social de grupos de ciudadanos ecologistas en Europa y Norte América en pos de una ética ambiental (Greenpeace, Los amigos de la Tierra, etc.) y los acuerdos ratificados en Las Cumbres de la Tierra organizadas por la ONU desde 1992, el desarrollo de una estrategia mundial de sostenibilidad de los ecosistemas es aún una de las grandes tareas de la humanidad. Así que, después de todo, la idea de que hemos entrado en una nueva era geológica, caracterizada por el impacto de la humanidad en la atmósfera, los océanos y la vida silvestre de la Tierra, implica una reevaluación drástica de la relación de la humanidad con el mundo natural (Bonneuil y Fressoz, 2017).

Desde el ámbito del arte y la producción cultural ha habido artistas pioneros que reflexionan sobre el cambio climático en las décadas de 1960 y 1970. Entre ellos se podrían señalar "Los Harrison" quienes trabajaron con biólogos, arquitectos y planificadores urbanos para proponer soluciones de apoyo a la biodiversidad y al desarrollo comunitario o Herman Prigann creador del parque de esculturas The Rheinelbe Sculpture Woods en unas viejas minas de Alemania (1996-2005). En los últimos años los gestores culturales responden al contexto de cambio climático incluyendo artistas en los programas de las Cumbres de la Tierra o desarrollando proyectos como Cape Farewell de David Buckland, que desde 2001 en Londres, reúne creativos, científicos e informadores para estimular narrativas para una sociedad futura sostenible. Todas estas iniciativas abren posibilidades de imaginar la relación entre práctica científica y artística extendiendo el pensamiento hacia los procesos ambientales a gran escala y surgen interensatísimas e inspiradoras propuestas que van dando sentido a ese giro en nuestra percepción de otras escalas temporales oceánicas y geológicas. Unos anuncian futuros distópicos de singularidad biotecnológica, como Anna Dimitri y Alex May (2018) en Archaeabot, un robot dotado de sofisticadas innovaciones en inteligencia artificial y pensada como la especie definitiva. Otros visualizan una singularidad temporal, como la desaparición de la Isla Nuuk en Groenlandia de Anaïs Tondeur (2014), quien a través de imágenes de laboratorio y de viajes de campo narra una colisión entre la escala de tiempo de la humanidad y la de los océanos. 
Estas exploraciones artísticas en la geología y los límites planetarios también pueden extenderse, como señalan Armiero y De Angelis (2017), a los estratos biológicos y genéticos, a los cuerpos fruto de la explotación, la subordinación y las desigualdades. Estos estratos están encarnados, en gran medida, en la memoria oral de un lugar y una época, son relatos que incorporan las experiencias y las historias de vida particulares de una comunidad y de sus representantes. Volviendo a los ciclos del carbono y a algunos de sus protagonistas, sería posible visualizar esas trazas del Antropoceno en las voces de aquellos que componen el sector siderometalúrgico y que hacen posible los materiales y combustibles de los que las sociedades contemporáneas dependen. ¿Qué relación entre práctica artística, científica y ciudadana lo haría posible? ¿Cómo amplificar esas voces mediante los lenguajes del arte? ¿Cómo se sitúa el viejo sector de la industria pesada europea en el Antropoceno? ¿Qué hilo narrativo conecta esta tragedia local a las nuevas escalas temporales globales? Este artículo trata de responder a estas preguntas y hace una reflexión sobre la aportación de las prácticas artísticas al debate del Antropoceno en base a los resultados de una investigación en la que han colaborado artistas, científicos sociales y ciudadanos. En un contexto global de cambio climático y de declive de la industria pesada local, la investigación llevada a cabo trata de crear una representación artística de las identidades colectiva laborales mediante la escucha de algunas voces discordantes del sector de la industria del acero en Europa. El manejo de testimonios orales en su dimensión estética y sonora abre posibilidades de imaginar y extender el pensamiento hacia el conflicto energético y climático global.

\section{PROCESOS, MÉTODOS Y RESULTADOS}

Algunos de los estudios en ciencias sociales que analizan el sector siderometalúrgico se basan en entrevistas con los agentes involucrados. Su objetivo es buscar respuestas en el testimonio de aquellos que componen el sector y que hacen posible los materiales y combustibles de nuestra era. Este es el caso de una investigación llevada a cabo por la socióloga y politóloga de la Universidad de Oviedo Mona Aranea entre 2015 y 2017 dentro del programa europeo Marie Curie. Su estudio examina la identidad, el discurso y las estrategias de los actores de las relaciones laborales europeas en los sectores siderometalúrgicos a nivel transnacional y se enfoca en las dinámicas de representación laboral, diálogo social y democracia industrial. Durante su trabajo de campo, Aranea realizó entrevistas a trabajadores/as directivos/as y representantes sindicales de Alemania, Bélgica y España en la compañía de producción de acero Arcelor Mittal y en la aseguradora Alliance. Estos registros de voz abrieron la posibilidad de llevar a cabo la triple tarea de la representación artística, científica y política en «Diálogo social. Una polifonía del mundo de la industria», un proyecto que propone una mirada artística al sector de la industria y trata de facilitar el nexo entre la universidad y la esfera pública. Los investigadores mostraron una gran confianza al dejarnos entrar en su entorno de investigación y de forma intuitiva vieron señalados en nuestro proyecto los aspectos no lógicos, dramáticos, humorísticos y poéticos de su propia tradición (Lopes, 2015). Su actitud durante todo el proceso fue la de explorar las lógicas asociativas que implica un proceso artístico y dejaron a nuestro criterio todas las decisiones sobre los elementos materiales expresivos, encuadres, tiempos y espacios. Sin embargo, fue necesario hacerles comprender la necesidad de buscar las cualidades estéticas y subjetivas de las voces y el sonido y no necesariamente su literalidad o su carácter documental. Sin perder las raíces, se dio un intercambio en el que ofrecimos nuestras contribuciones artísticas poco ortodoxas, al mismo tiempo que los científicos nos enseñaron sus modos de hacer. Esta iniciativa culminó dos años después en una instalación sonora abierta al 
público durante dos meses en una sala de Laboral Centro de Arte y Creación Industrial (Gijón) (Figura 1). El trabajo creativo fue desarrollado por los artistas Lorena Lozano y Juanjo Palacios (asociación cultural Econodos. Ecología y comunicación) en estrecha colaboración con Aranea y su supervisor, el Dr. Holm-Detlev Köhler (PROMEBI, grupo de investigación para la promoción del empleo y el bienestar en Europa, Universidad de Oviedo).

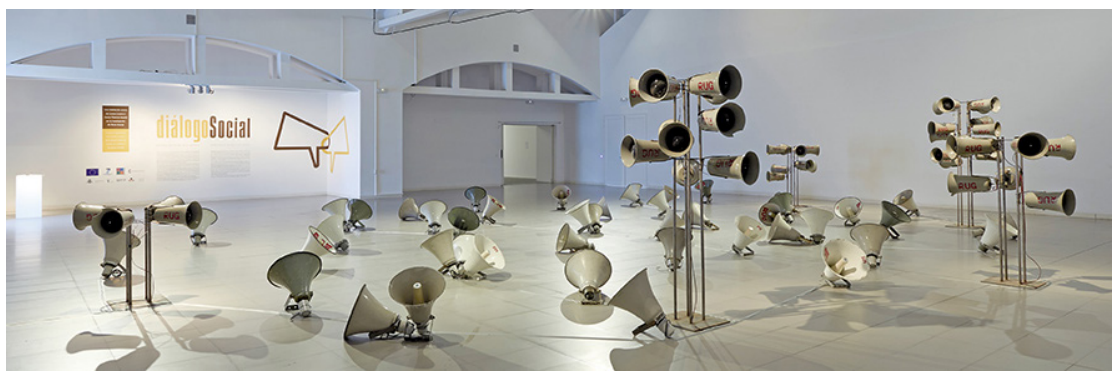

Figura 1. Marcos Morilla, vista general de la instalación sonora en Laboral Centro de Arte y Creación Industrial (Gijón).

El proceso comenzó con la obtención del consentimiento informado para el uso de las voces de las personas entrevistadas. Esto supuso someter los contenidos a una auditoría que provocó diferentes respuestas y mientras hubo quienes se comprometieron con entusiasmo, otros, por incompatibilidad con sus intereses corporativos descartaron la colaboración. Como consecuencia, los testimonios con los que contamos pertenecen a representantes sindicales, trabajadores y directivos por lo que mantienen un sesgo hacia los intereses laborales de las personas trabajadoras, las dificultades en la gestión y en la aplicación de las normativas climática y energética. El material de partida fueron 13 audios de entrevistas en las que participan 16 personas y sus respectivas transcripciones, el tono es formal y serio y fueron grabadas en la cafetería de una fábrica en Bremen y oficinas en Bruselas, Avilés y Madrid, por lo que se aprecian ruidos de fondo, tazas, gente hablando, sirenas de una fábrica, etc. Tras la escucha atenta de los primeros audios fue posible detectar un gran componente evocador en las grabaciones de voz, su poder de identificación con realidades laborales históricas y la dimensión ambiental a gran escala siempre de fondo. La edición de las entrevistas consistió en la alteración del testimonio oral, fundamento del método etnográfico, como una forma de abrir otras dimensiones estéticas a estas voces y un nuevo discurso. Para ello seleccionamos fragmentos que, por los contenidos, la vehemencia y la expresividad de las palabras sintetizaban las problemáticas más señaladas. Nuestro objetivo era amplificar sus voces y crear una representación de sus cualidades expresivas, afectivas y emocionales, al mismo tiempo que recrear la falta de consenso y la dificultad de conseguir una única voz. Para ello jugamos con formatos, medios y estéticas capaces de generar nuevas formas espaciales y un nuevo conocimiento perceptivo (Carles, 2010).

En este nuevo relato desvelamos la inconformidad de sindicalistas, directivos y trabajadores de aseguradoras frente a las negociaciones y acuerdos no vinculantes rescatando expresiones que se repiten una y otra vez como speaking with one voice...convergencia de intereses...hay que reinventarse...nuevos contextos de negociación...binding agreements...compromise... common ground...joint position...discuss...decisión...confrontation...not an easy consensus... Todos ellos se lamentan por las dificultades idiomáticas de la Unión Europea en locuciones como...interpretation...translation....y mientras los sindicalistas españoles hablan con extrañeza 
de los desiertos industriales del paisaje que surgen cuando toda una región cesa su actividad de producción de acero, dos trabajadores de una fábrica en Bélgica repiten en un inglés muy poco fluido las palabras trust...rights...solidarity...strike...anger... Los cierres de las fábricas como solución al abaratamiento de costes se manifiestan con decepción e indignación, especialmente en el testimonio de un sindicalista belga quien usa juegos de palabras como "pull the plug» (desenchufar), aludiendo al mismo tiempo, y de forma irónica, al cierre de una factoría y a la crisis energética. También usa la expresión francesa compétitif prix, compétitif hors prix para referirse a la paradójica relación entre costes de la fuerza de trabajo y poder...out of labour cost...precio energía y coste de trabajo y califica a los magnates de las corporaciones multinacionales como massive oligarchies...the power are they...La cuestión climática y energética es acometida por las trabajadoras de las aseguradoras, las cuales no consiguen cumplir los acuerdos por el clima y las emisiones. El continuo murmullo en su discurso reitera...climate policies.... $\mathrm{CO}_{2}$ emissions permits...power sector...política industrial y política energética...mientras discuten el precio de la energía, el de la fuerza de trabajo y el de la calma social...the price for social peace... También aluden a la salud de los trabajadores refiriéndose al stress, health and safety y a la situación de las comunidades cuando ya no hay empleo...life long learning...relevo generacional...vocational, educational and training...women in steel industry... community...el empleo es local...transfer the know-how...anticipation of change...

Cada fragmento seleccionado tiene una duración de entre 4 y 30 segundos y con todos ellos elaboramos tres pistas de audio de entre 25 y 30 minutos cada una que contienen las palabras de 4 o 5 entrevistados. Estas tres pistas de audio son emitidas en bucle y simultáneamente de forma que el resultado final que se escucha son conversaciones entrecortadas y solapadas de hombres y mujeres que hablan español e inglés (Figura 2).
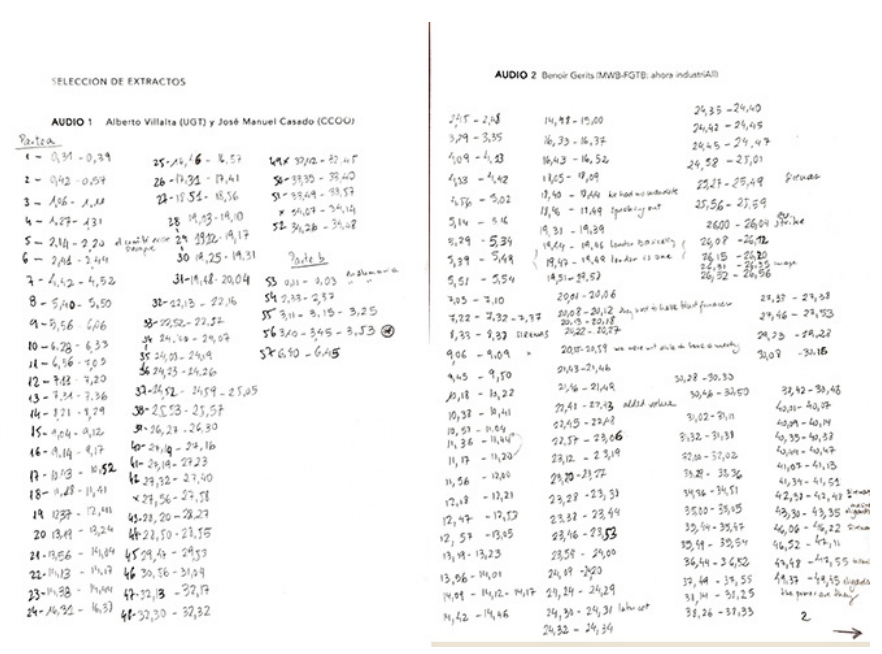

Figura 2. Lorena Lozano. Anotaciones de las secuencias temporales seleccionadas. Escaneado, 2017. (Fuente: archivo de Econodos).

Paralelamente a la conceptualización y edición de los contenidos de las entrevistas buscamos un artefacto con el que emitir sonido que visualmente fuese poderoso y fácil de vincular al imaginario colectivo industrial. Por ello decidimos que nuestro gran significante visual sería el altavoz unidireccional, unos objetos cargados de simbología que nos remite a las fábricas, 
la arquitectura de control y las reivindicaciones sociales. La empresa Radio Unión Gijón nos ofreció usar sus equipos, unos 80 altavoces que contienen una inscripción de color rojo con las iniciales RUG en la campana. Esta gráfica es totalmente diferente al actual logo de la empresa y pensamos que su recontextualización en la sala de un centro de arte podría reforzar la escena al interpretase como una onomatopeya del rugido o por evocar una estética política. Con el apoyo del equipo técnico de Laboral Centro de Arte y Creación Industrial y de Radio Unión Gijón conseguimos conectar y emitir sonido por los altavoces (Figuras 3 y 4 ).
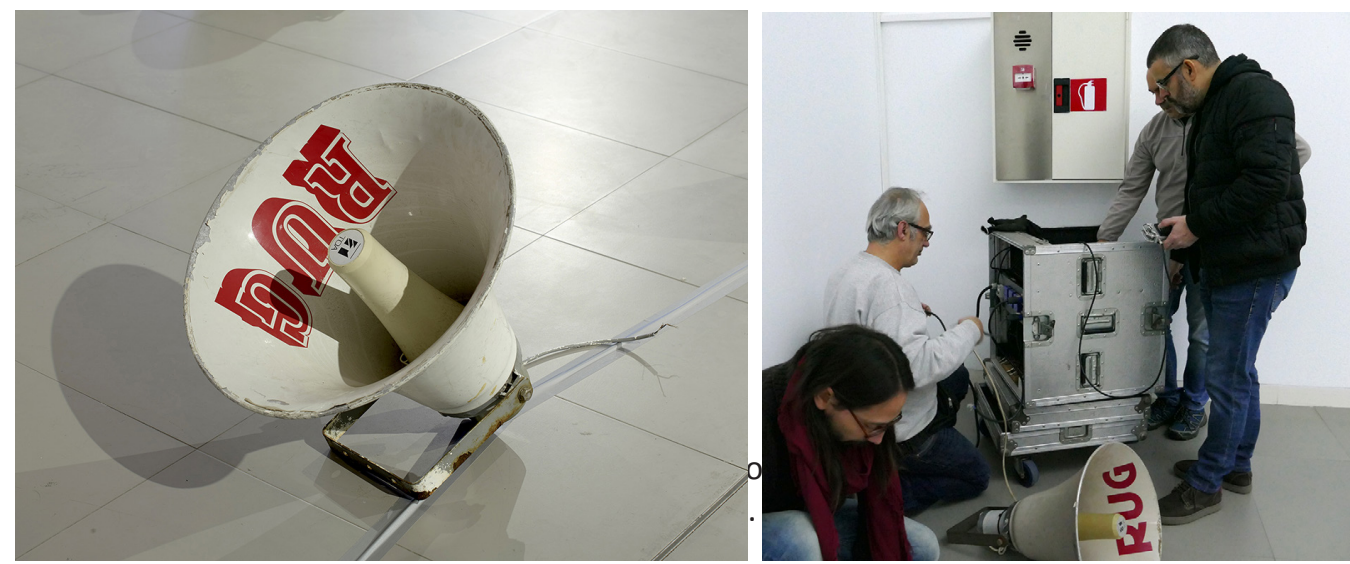

Figura 3. Marcos Morilla. Altavoz exponencial. Fotografía digital, 2017. (Fuente: archivo de Econodos).

Figura 4. Lorena Lozano. Instantánea del montaje. Fotografía digital, 2017. (Fuente: archivo de Econodos).

Intervinimos una de las enormes salas del centro mediante una composición espacial y visual en la que colgamos los altavoces más pequeños en unas viejas torres de metal y ordenamos el resto por el suelo creando una red de información no distribuida. De forma deliberada el sonido no llega a todos los altavoces, algunos están claramente desconectados como una interpretación literal de las manifestaciones de interlocutores, quienes en ocasiones no consiguen que sus reivindicaciones sean escuchadas en los canales de toma de decisiones. Inicialmente pensamos en dejar el cable visto, simplemente posado sobre el pavimento de la sala, queríamos ser fieles a nuestra tecnología, sin esconder o teatralizar el encuentro. Sin embargo, por cuestiones de seguridad, usamos cinta para fijarlo en el suelo para evitar posibles tropiezos y accidentes cuando la audiencia interaccionase y caminase entre los altavoces. Manejamos la iluminación con cierto dramatismo, pero sin exagerar y usamos una imagen gráfica con la que comunicar y difundir el trabajo a modo de diagrama de gauss que entrelaza las siluetas de dos megáfonos o bocadillos de una conversación (Figuras $5,6,7,8$ y 9).

La última parte del montaje consistió en ajustar el paisaje sonoro a la escenografía que habíamos creado y por ello quisimos, ofrecer al público la experiencia de un relato sobre la decadencia de un sector económico y sus agentes. Emitimos las conversaciones entrecortadas y solapadas de hombres y mujeres que hablan español e inglés a un volumen extrañamente bajo que provoca un inicial desconcierto en el público. Esto obliga a la audiencia a acercarse a escuchar y a pasar aleatoriamente de un altavoz a otro, tratando de poner en evidencia las voces de los protagonistas como fantasmas del pasado, como hilos de voz que desaparecen en el Antropoceno (Figura 10). 

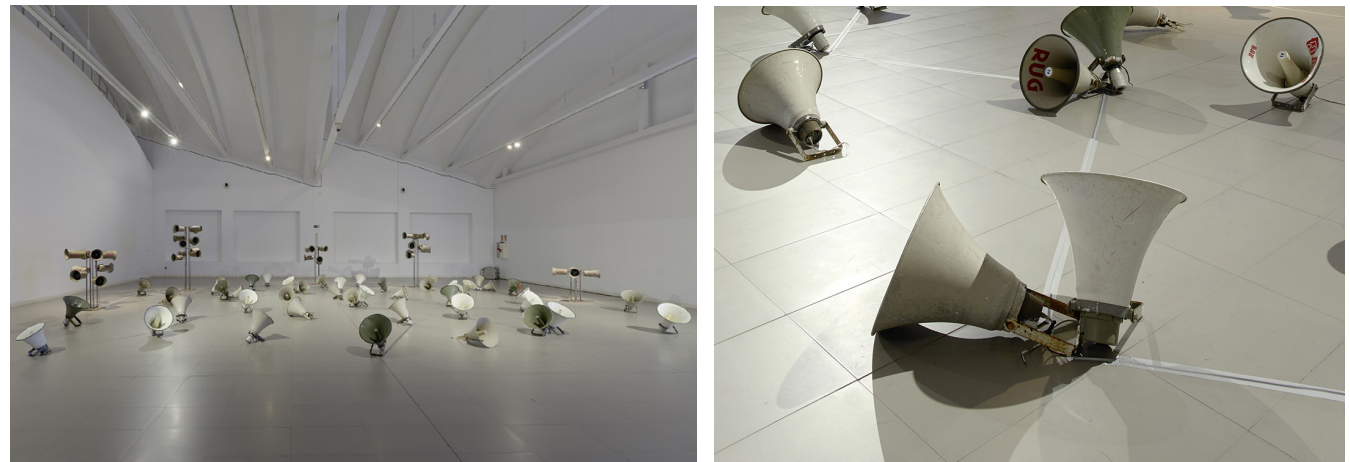

Figura 5. Marcos Morilla. Distribución de altavoces en el espacio. Fotografía digital, 2017. (Fuente: archivo de Econodos).

Figura 6. Marcos Morilla. Detalle del cableado. Fotografía digital, 2017. (Fuente: archivo de Econodos).
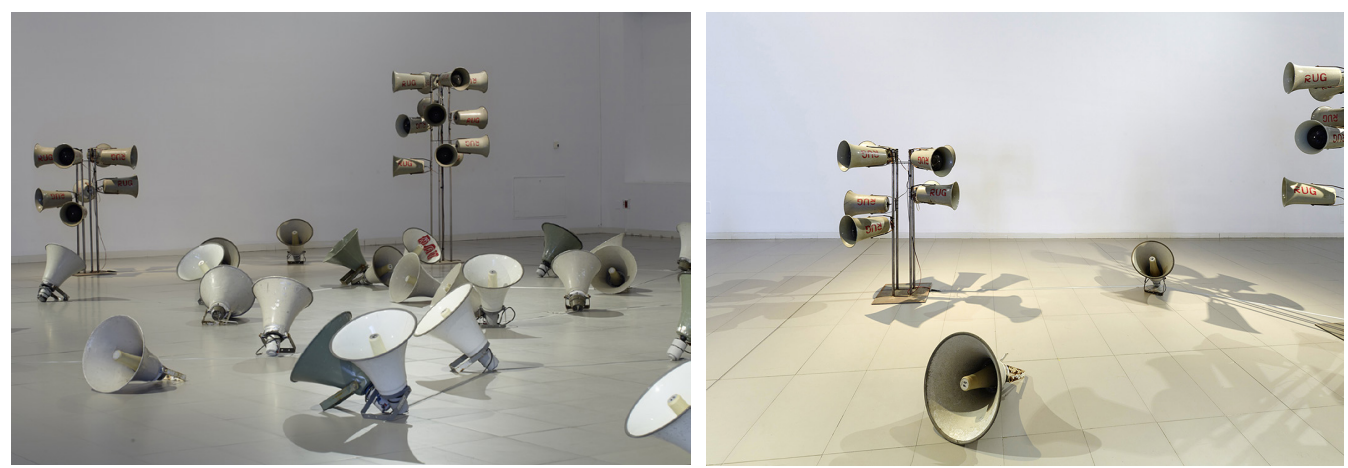

Figura 7. Marcos Morilla. Vista de la exposición. Fotografía digital, 2017. (Fuente: archivo de Econodos).

Figura 8. Marcos Morilla. Detalle de la iluminación. Fotografía digital, 2017. (Fuente: archivo de Econodos).

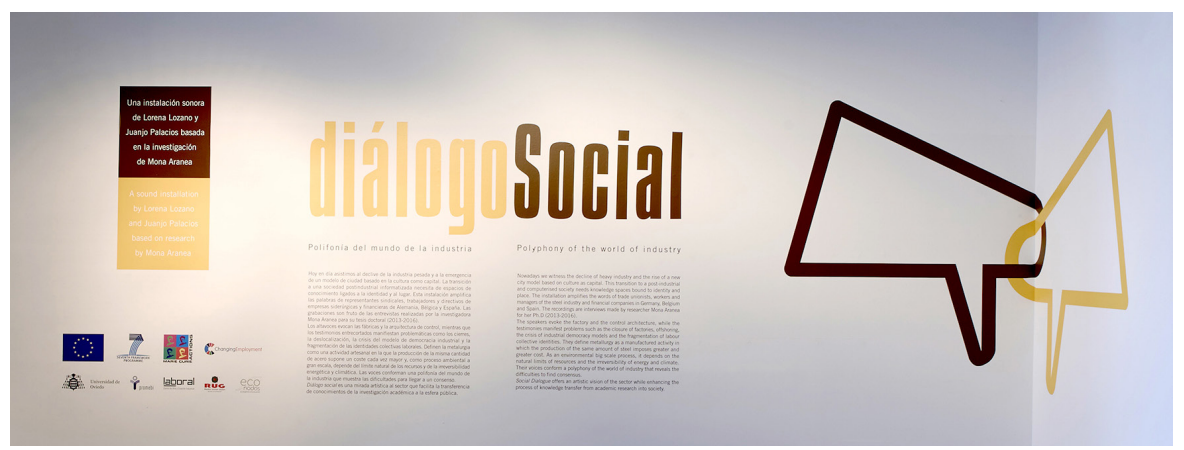

Figura 9. Detalle de la gráfica. Fotografía digital, 2017. (Fuente: archivo de Econodos). 

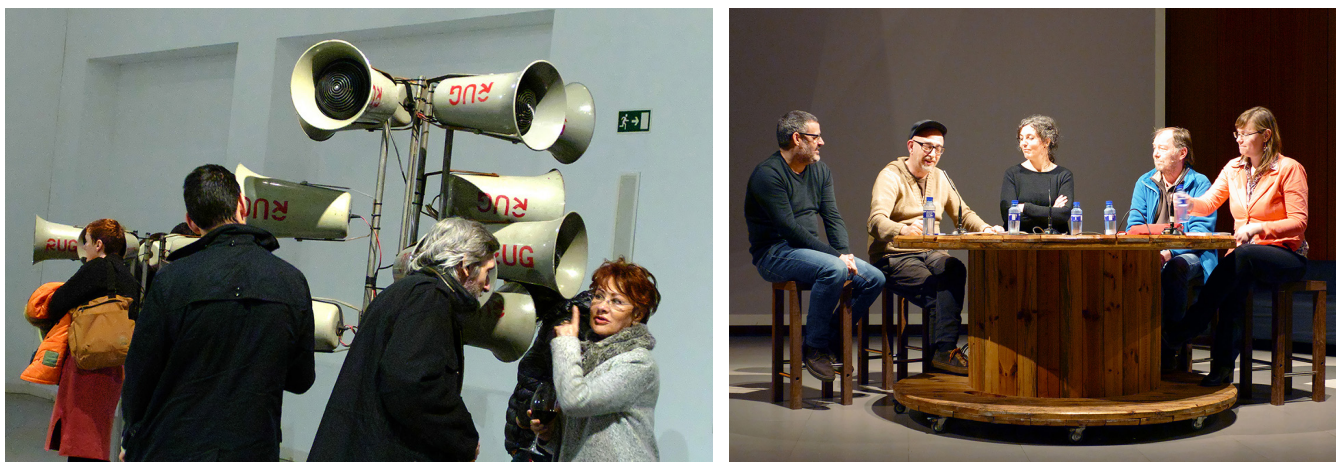

Figura 10. Lola G. Zapico. Escuchando en la inauguración. Fotografía digital, 2017. (Fuente: archivo de Econodos).

Figura 11. Lola G. Zapico. Mesa de debate, de izquierda a derecha, Juanjo Palacios, Jorge Luis Marzo, Lorena Lozano, Holm Khöler y Mona Aranea. Fotografía digital, 2017. (Fuente: archivo de Econodos).

Durante el acto de inauguración abrimos una mesa de debate sobre el declive de la industria pesada y la emergencia de la industria cultural en la que estuvimos presentes los artistas e investigadores del proyecto junto al historiador del arte Jorge Luis Marzo (Figura 11). El público asistente fue una combinación de profesionales del arte y la cultura, investigadores de sociología, ciencias políticas y económicas y representantes sindicales del sector siderúrgico de la región. El debate que se abrió puso sobre la mesa la experiencia de colaboración entre la investigación en ciencias sociales y el arte, la incertidumbre de las relaciones laborales de la cultura, la reivindicación de conceptos históricos como sindicato, trabajador/a o pueblo o la crisis económica que sufre Asturias. Como colofón editamos una publicación en papel de 200 ejemplares que fue apoyada por (Lozano et al, 2017). Su distribución se realizó en la página web de Econodos, las mediatecas del MUSAC (León) y de Laboral Centro de Arte, la biblioteca de la facultad de humanidades y de ciencias jurídicas de la Universidad de Oviedo, la biblioteca de la facultad de Bellas Artes de la UCM y todos los agentes que había participado y cedido sus voces.

\section{LAS POLÍTICAS DEL TRABAJO Y LAS DE LOS OBJETOS MATERIALES}

Las fábricas de acero mencionadas en las entrevistas se localizan en Florance y Lieja (Bélgica), Avilés y Zumárraga (España), Bremen (Alemania), entre otras, y forman parte de un contexto de 150 años de historia industrial de la minería y la siderurgia. Las comunidades humanas que habitan esos lugares están conformadas alrededor de un sector económico ahora en declive y en difícil transición de sociedad agraria y post industrial a sociedad metropolitana e informatizada. Ante la premura de los costes energéticos y humanos, están a expensas del cierre de factorías en Europa y la localización de la producción en Asia, lo que conlleva su preocupación por las condiciones de trabajo, las pensiones, etc. Las diferencias lingüísticas entre los países involucrados hacen difícil el diálogo con las instancias de poder que otorga la UE y su labor como interlocutores transnacionales es la de mediar entre formas de cálculo económico y regulación gubernamental. Los mismos metales sobre los que discuten parecen desvanecerse inmersos en flujos de información y conocimiento que regulan su extracción, manufactura, uso, reparación y costes energéticos y humanos. Hablan del acero como objeto de controversia y las voces perfilan la identidad del metalúrgico como un experto en el análisis de las propiedades de los materiales. Afirman que los procesos físico-químicos son, hasta 
cierto punto, imprevisibles y frágiles y, por ello, la metalurgia es una actividad artesanal que ha de atender a la especificidad local.

El cierre de factorías que mencionan los entrevistados se traduce en desiertos industriales que yacen sobre los paisajes del carbono que comenzaron a formarse hace millones de años en su lento proceso de fosilización. Paisajes no renovables de la materia que, mediante el proceso de carburización inverso, producen un imborrable impacto en la regulación del clima de la Tierra. Paisajes de la energía que obligan a hablar de su conversión en trabajo, calor y eficiencia en base a las leyes de la termodinámica, las cuales, desde el siglo XIX, enuncian que la energía ni se crea ni se destruye, solo se transforma y que cuando un sistema cambia de estado, su entropía o desorden interno aumenta. Al aplicar estos principios a la siderurgia, se comprueba la imposibilidad de construir una máquina térmica que, operando en un ciclo, no produzca otro efecto que la absorción de energía desde un depósito y la realización de una cantidad igual de trabajo. Una lógica que advierte de un fenómeno claramente limitante: cada vez costará más extraer la misma cantidad de trabajo. ¿cantidad de trabajo? ¿ o de producción? El estudio de los flujos de energía en los sistemas demuestra que una auténtica sustentabilidad supone necesariamente minimizar el nivel de entropía y pensar a largo plazo respetando los límites de lo que tomamos de la biosfera y de lo que le devolvemos como residuos (Riechmann, 1995, en San Martín Segura, 2003). Algo que subyace en el diálogo entrecortado que mantienen nuestros protagonistas como una gran tensión global-local en un sector económico cuyo gran obstáculo radica en los fenómenos limitantes de la energía y el clima.

El estudio de Aranea concluye que la evolución de las relaciones laborales, como tradicionalmente sucede, está marcada por la divergencia de posturas entre las partes trabajadora, sindical, política y empresarial. Pensar en una democracia industrial transnacional necesitaría de identidades colectivas laborales fuertes y una cultura corporativa que favorezca el diálogo antes que el conflicto (Aranea, 2017). Sin duda un gran desafío ante el declive de la industria pesada en Europa y la consolidación de modelos de desarrollo urbano que se basan en la cultura como capital. En la sociedad red, la fábrica es Internet, como forma de organización y economía consistente en flujos de información y conocimientos. Las industrias culturales mantienen la producción y difusión de innovaciones que se deslocalizan y organizan en un tiempo global real. Los nuevos espacios de conocimiento ligados a la identidad y al lugar son, según el historiador Jorge Luis Marzo (2017), réplicas de la eterna precariedad del trabajo, pero regulada ahora por la nueva economía de la creatividad y de la industria del signo. Sectores como el diseño, la comunicación audiovisual, el dominio digital, el arte, la literatura, la academia y las instituciones culturales se enredan en la perversa comodidad del teletrabajo que se convierte en más productividad, adaptabilidad, innovación, creatividad y entusiasmo. Bajo la supuesta desmaterialización de la economía y desacoplamiento entre crecimiento económico y consumo de recursos, la realidad es el aumento de la extracción de minerales, su procesado y desechado mientras la eficiencia energética está por resolver (García, 2004). El modelo actual de desarrollo urbano evidencia su dependencia energética y el consiguiente conflicto económico, político y gubernamental. El acero, ese filo de arma blanca, nos conduce a reflexionar en torno a las políticas del trabajo y las de los objetos materiales; las primeras ensamblan lo social y lo material generando conflictos que afectan a las relaciones entre gobiernos, corporaciones y ciudadanos (Andrew, 2010). Las segundas podrían ser una oportunidad de repensar el concepto de materialidad analizando la energía - además de la vida, la cultura o la información- desde una dimensión ética que atañe no solo a los políticos, y empresarios sino también a los científicos, físicos, químicos e ingenieros (Stangers, 2010, en Knox y Huse, 2015). 


\section{CONCLUSIONES}

La labor de producción cultural supone negociar los intereses de las instituciones involucradas, las agendas, los cronogramas, las burocracias y los fondos. El proceso nos sumió en conversaciones con todos los agentes implicados: artistas, investigadores sociales, trabajadores, sindicalistas, técnicos y directivos de factorías de acero europeas y de aseguradoras, así como los gestores del centro de arte que hospedaron el resultado final. Fuimos observadores críticos de la magnitud de los conflictos que atañen a la producción del acero a nivel mundial y del marco institucional europeo, de la investigación social y de la producción del arte contemporáneo. Pudimos constatar que la relación entre práctica artística y científica es posible en la academia mediante espacios interesados en acoger alternativas a la idea de la ciencia como verdad absoluta y del arte como una visión privilegiada de la modernidad. La contribución del arte a los debates políticos y ambientales globales permite moverse del pensamiento subjetivo al objetivo algo totalmente necesario para generar representaciones y narrativas, acercar audiencias, traducir mensajes, amplificar voces y registrar testimonios. Estos métodos, junto a la incorporación de la monitorización y las perspectivas de la ciencia ayudan a definir nuevas preguntas y facilitan otros procesos de construcción de conocimiento. Nuestra propuesta hace una interpretación estética de los registros de audio efectiva y provocativa, que revela dimensiones escondidas de la vida social. Al valor antropológico de los testimonios orales se le suma la capacidad evocativa del sonido y la acción de la escucha, algo ya explorado por las vanguardias artísticas del siglo XX, desde Luigi Russolo (1913), quien abre especial atención a ruidos y palabras de las calles como señas de identidad, a la experimentación dadaista, la ecología acústica de Murray Schafer (1968), el apropiacionismo sonoro de Jon Leidecker (2009) o emisoras online de protestas como Escuchatorio (2015). Perspectivas del arte sonoro desde las cuales es posible construir una imagen de simpatía y solidaridad hacia el sector de la siderurgia y que evidencia las ambivalentes ideas de rechazo y felicidad que nos suscitan el carbón y el acero. En ellas reside la mayor aportación al debate, encarnar al Antropoceno en las voces fruto de la explotación, la subordinación y las desigualdades.

Las identidades colectivas laborales que Aranea subraya fueron representadas en nuestro trabajo como ilustres personajes de una tragedia inevitable. Encontramos las trazas del Antropoceno en su eterno diálogo sobre viejas y nuevas problemáticas laborales y ambientales y sobre cómo el poder se relaciona con la crisis energética y climática. Es difícil no atribuir un velo de nostalgia a las luchas sindicales de la industria pesada en un escenario en el que están afectados por un proceso de reacomodamiento estructural, simbólico y jerárquico. Son voces históricas locales cuya experiencia aparece desvalorizada y sus sensibilidades y formas de organización social y cultural no se corresponden con las actuales. Quizás estamos presenciando la extinción de un viejo sector industrial en Europa, una suerte de «histéresis» o «efecto don Quijote» en el que hay un esfuerzo por adivinar viejos fantasmas, gigantes añorados que no terminan de conformarse (Martín Criado, 2009) y se diluyen en el Antropoceno, en esa perspectiva hiperglobal que hace que el tiempo histórico pierda valor e invisibiliza los conflictos del día a día de la vida social. «El Antropoceno será corto» dice Haraway (2016) mientras nos hace imaginar un evento fronterizo, una estrecha capa en los estratos de la corteza terrestre, similar al impacto del asteroide que provocó la extinción de dinosaurios y de otros taxones hace 66 millones de años. Sin duda, ha pasado ese momento en el que se podían observar los grandes fenómenos naturales y cómo se habían ido desarrollado. Parece ser que estamos presenciando un período de aceleración sin precedentes, la escala de tiempo humana ya no puede verse como distinta de la escala de tiempo 
del sistema terrestre. Ahora el tiempo disminuye y podemos observar las fuerzas humanas en aquello que parecía inalterable. Quizás uno de los ejercicios del Antropoceno sea precisamente ese, el de relativizar la escala temporal, algo que hicieron los movimientos ecologistas mediante su identificación como especie y su percepción ahistórica del tiempo. Quizás la alarma no sea más que una de las múltiples y renovadas caras de la misma moneda, la de una crisis sistémica en la que subyace la fragilidad de la vida en el planeta. 


\section{Bibliografía}

Andrew, B. (2010). Materialist politics, metallurgy. En B. Braun y S. J. Whatmore (Eds.), Political Matter. Technoscience, Democracy, and Public Life. Minneapolis: MIT Press. University of Minnesota Press.

Aranea, M. (2017). Las relaciones laborales europeas como arenas de poder multinivel. Democracia industrial transnacional en Arcelormittal y Allianz SE. Tesis Doctoral. Universidad de Oviedo.

Aranea, M. (2017). Identidades laborales colectivas. En Diálogo social. Polifonía del mundo de la industria (pp. 12-13). Gijón: Econodos.

Armiero, M. y De Angelis, M. (2017). Anthropocene: victims, narrators, and revolutionaries. South Atlantic Quarterly, 116(2), 345-362. DOI: https://doi.org/10.1215/00382876-3829445

Avendaño, J.P. (2015). Escuchatorio. Recuperado el 3 de octubre de 2018 de: http://www.escuchatorio.net/

Bonneuil, C. y Fressoz, J.B. (2017). The Shock of the Anthropocene. Londres: Verso 2017.

Carles, J.L. (2010). Mapas y representaciones sonoras. Contribuciones y evolución. Zehar, 67, 108-117.

Carruthers, J. (2016). The Anhropocene. Royal Society of South Africa. Recuperado el 3 de octubre de 2018 de: http://www. royalsocietysa.org.za/?page_id=2292

Crutzen, P.J. y Stoermer, E.F. (2000). The Anthropocene. IGBP Global Change Newsletter, 41, 17-18. Recuperado el 3 de octubre de 2018 de: http://www.igbp.net/download/18.31 6f18321323470177580001401/1376383088452/NL41.pdf

Desoto, P. (2016). Antropoceno, Capitaloceno, Chthuluceno, viviendo con el problema en Fukushima. Tesis Doctoral (Doutorado em Comunicação e Cultura) - Escola de Comunicação, Universidade Federal do Rio de Janeiro.

García, E. (2004). La sociología ecológica o medioambiental. En Medioambiente y sociedad: La civilización industrial y los límites del planeta (pp. 59-100). Madrid: Alianza Editorial. 
Haraway, D. (2016). Manifiesto Chthulueno desde Santa Cruz. Revisado de Donna Haraway y Cary Wolfe en Conversación. Santa Cruz: El Planeta Laboratorio. Recuperado el 3 de octubre de 2018 de: https://laboratoryplanet.org/es/manifeste-chthulucene-desanta-cruz/

Knox, H. y Huse, T. (2015). Political materials: rethinking environment, remaking theory. Distinktion: Journal of SocialTheory, 16(1), 1-16, DOI: https://doi.org/10.1080/160091 OX.2015.102841

Leidecker, J. (2009). Entrevista con Jon Leidecker sobre apropiacionismo sonoro. Barcelona: Arte nuevo. Recuperado el 14 de abril de 2019 de: http://arte-nuevo.blogspot.com/2009/12/ entrevista-con-jon-leidecker-sobre.html

Lopes, M.M. (2015). Intertwined artistic practices: critical remarks on collaboration across fields of knowledge. MIDAS. Museus e estudos interdisciplinares [Online], 5. Recuperado el 15 de enero de 2018 de: http://midas.revues.org/856 DOI: 10.4000/ midas. 856

Lozano, L., Aranea, M. y Marzo, J.L. (2017). Diálogo social. Polifonía del mundo de la industria. Gijón: Econodos. Recuperado el 26 de junio de 2019 de: https://www.econodos.net/wpcontent/uploads/2017/11/dialogoSocial_catalogo.pdf

Lozano, L. (2018). Diálogo Social entre la práctica artística y la investigación académica. Revista Accesos, 1, 58-65.

Martín Criado, E. (2009). Habitus. En R. Reyes (Dir.): Diccionario Crítico de Ciencias Sociales. Terminología Científico-Social, Tomo 1/2/3/4, Madrid-México: Ed. Plaza y Valdés. Recuperado el 3 de octubre de 2018 de: https://webs.ucm.es/info/eurotheo/ diccionario/H/habitus.htm.

Marzo, J.L. (2017). «Des-». En Econodos (Ed.). Diálogo social. Polifonía del mundo de la industria (pp. 18-19). Gijón: Econodos.

Russolo, L. (1913). El arte de los ruidos. Manifesto futurista. En Monoskop. Recuperado el 14 de abril de 2019 de: https:// monoskop.org/images/6/69/Russolo_Luigi_El_arte_de_los_ ruidos_Manifiesto_Futurista.pdf

San Martín Segura, D. (2003). Apuntes para un análisis ecológico de las formas de política contemporáneas. Redur 1, 251-300. 
Schafer, M. et al. (1968). World Soundscape Project. Vancouver: Simon Fraser University. Recuperado el 14 de abril de 2019 de: https://www.sfu.ca/sonic-studio-webdav/WSP/index.html

Tondeur, A. (2014). Lost in phantoms. París: Anaïs Tondeur. Recuperado el 7 de mayo de 2019 de: http://www.anais-tondeur. com/projects/lost-in-fathoms--nuuk-island/

Zalasiewicz, J. et al. (2016). Working Group on the 'Anthropocene'. Subcommission on Quaternary Stratigraphy of the International Union of Geological Sciences (IUGS). Recuperado el 3 de octubre de 2018 de: http://quaternary.stratigraphy.org/working-groups/ anthropocene/ 